\title{
Imaging features of the aging spine
}

\author{
Krzysztof Wocial ${ }^{1 A, B, D, E, F}$, Beata A. Feldman ${ }^{1 D, E}$, Bartosz Mruk ${ }^{2 E}$, Katarzyna Sklinda ${ }^{2 E}$, Jerzy Walecki ${ }^{1,2 A, D, E, F}$, \\ Marcin Waśko ${ }^{1 A, B, D, E, F}$
}

'Department of Diagnostic Imaging, Gruca Teaching Hospital, Medical Center of Postgraduate Education, Otwock, Poland

2Department of Diagnostic Radiology, Central Clinical Hospital of the Ministry of the Interior in Warsaw, Poland

\begin{abstract}
Among many degenerative abnormalities commonly found in spine imaging, not all are associated with the patient's symptoms. We aimed to assess features of the standard, asymptomatic aging process of the spine. In this narrative review, we emphasize studies that describe imaging features of the spine in asymptomatic populations of different age groups. Degeneration of the intervertebral discs, bulging, and facet joint arthropathy have been documented in almost $90 \%$ of asymptomatic patients over 60 years of age. After the age of 40 years, nearly all patients have anterior and lateral vertebral osteophytes, whereas posterior osteophytes are found in a minority of them. There is a gradual increase in vertebral bone marrow fat composition with age with the acceleration of this process in women after menopause. The prevalence of these findings is common in asymptomatic populations and varies depending on the patient's age. It is essential to differentiate likely natural and age-related findings from pathological abnormalities to make an accurate diagnosis.
\end{abstract}

Key words: aging, spine, MRI, asymptomatic.

\section{Introduction}

Morphological changes of the spine resulting from aging are natural and progressive processes [1-3]. Aging is also a risk factor for the development of osteoarthritis of the spine, during which degeneration of intervertebral discs, vertebral bodies, and intervertebral joints are often its first manifestations $[4,5]$. Therefore, the exact distinction between the physiological aging of the spine and its degeneration in the course of degenerative disease is not always straightforward. Clinicians need to pinpoint the culprits responsible for pain, suffering, and diminished quality of life, because findings from imaging studies might often trigger medical and surgical interventions [6].

Knowledge of the incidence and morphology of individual markers of spine aging in various age groups and within selected structures may aid in the differential diagnosis between symptomatic disease and asymptomatic changes related to aging alone. Therefore, this narrative review aims to provide an overview of the features related to the aging of the spine and distinguish them from pathological degenerative changes, based on the literature. Therefore, we aimed to answer the following questions: What is the prevalence of imaging findings associated with degenerative spine conditions in asymptomatic individuals? Which of these findings are strongly associated with older age despite an asymptomatic clinical picture? What is the typical image of the aging spine on magnetic resonance imaging (MRI)?

\section{Material and methods}

We reviewed articles located using the PubMed, EMBASE, and Google Scholar databases. The databases were searched for the following keywords: "aging", "asymptomatic", "magnetic resonance imaging”, "spine”, "intervertebral disc", “aging/pathology”, “degeneration”.

Correspondence address:

Krzysztof Wocial, Department of Diagnostic Imaging, Gruca Teaching Hospital, Medical Center of Postgraduate Education, Otwock, Poland,

e-mail: krzysztofw.wocial@gmail.com

Authors' contribution:

A Study design - B Data collection - C Statistical analysis · D Data interpretation - E Manuscript preparation · F Literature search · G Funds collection 
Inclusion criteria were as follows: published papers of all study designs, including the lumbar region of the spine, in Polish or English, with no years of restriction. Articles describing pathological or symptomatic spine disorders were excluded.

\section{Discussion}

\section{Intervertebral disc}

The intervertebral disc complex includes nucleus pulposus, annulus fibrosus, and adjacent cartilaginous endplate of the vertebral bodies $[4,7,8]$. The centrally located nucleus consists of $70-90 \%$ water. The remaining part consists of proteoglycans, type II collagen fibres, and loosely distributed chondrocytes located mainly in the endplate cartilage area [8]. At a young age, the nucleus makes up most of the intervertebral disc, while the annulus is narrow and well demarcated. Changes associated with the aging of the body are mainly due to a decrease in the hydration of the disc, especially the nucleus pulposus $[7,8]$ - the number of viable chondrocytes decreases, which translates into a decrease in the production of water-binding proteoglycans. At the same time, the relative collagen content increases. In MRI studies, this is manifested by a decrease in signal intensity in T2-weighted images, blurring of the boundary between the nucleus pulposus and the annulus fibrosus, and a decrease in disc height $[9,10]$. The above changes, characteristic of the progressive age-related degeneration of intervertebral discs, were graded by Pfirrmann on a five-grade classification, which is presented in Table 1 and Figures 1-5.

Foltz et al. suggest that the Pfirrmann classification might be subjective, thus failing to adequately capture primary degenerative changes. They propose quantitative MRI techniques using T2-intensity signal mapping among intervertebral discs, which allow evaluation of the initial stages of degeneration [11]. Moreover, some authors described diurnal variations in the intervertebral disc T2 signal and bulging that may lead to misinterpretation of intervertebral disc degeneration (IDD) $[12,13]$. Danielson and Willen reported a change in dural cross-sectional area while applying an axial load to the spine [14]. In another study, Pfirrmann et al. also described age-related changes in the shape and volume of the intervertebral discs on lumbar spine MRI in 70 asymptomatic volunteers with no back pain. They measured several parameters of intervertebral discs, including height, volume, and convexity index. Their study demonstrated that despite the lack of degenerative changes, the volume and height of discs decrease with age, and their shape becomes less convex [15]. Yang et al. analysed MRIs of 65 asymptomatic volunteers to evaluate the applicability of the distance between the nucleus' centre weighted by the signal intensity and

Table 1. Pfirrmann classification of lumbar disc degeneration

\begin{tabular}{|l|c|c|c|c|}
\hline Grade & Structure & Distinction of nucleus and annulus & Signal intensity & Height of intervertebral disc \\
\hline I & Homogeneous, bright white & Clear & $\begin{array}{c}\text { Hyperintense, isointense } \\
\text { to cerebrospinal fluid }\end{array}$ & Normal \\
\hline II & $\begin{array}{c}\text { Inhomogeneous with } \\
\text { or without horizontal bands }\end{array}$ & Clear & $\begin{array}{c}\text { Hyperintense, isointense } \\
\text { to cerebrospinal fluid }\end{array}$ & Normal \\
\hline III & Inhomogeneous, grey & Unclear & Intermediate & Normal to slightly decreased \\
\hline IV & Inhomogeneous, grey to black & Lost & Intermediate to hypointense & Normal to moderately decreased \\
\hline V & Inhomogeneous, black & Lost & Hypointense & Collapsed disc space \\
\hline
\end{tabular}

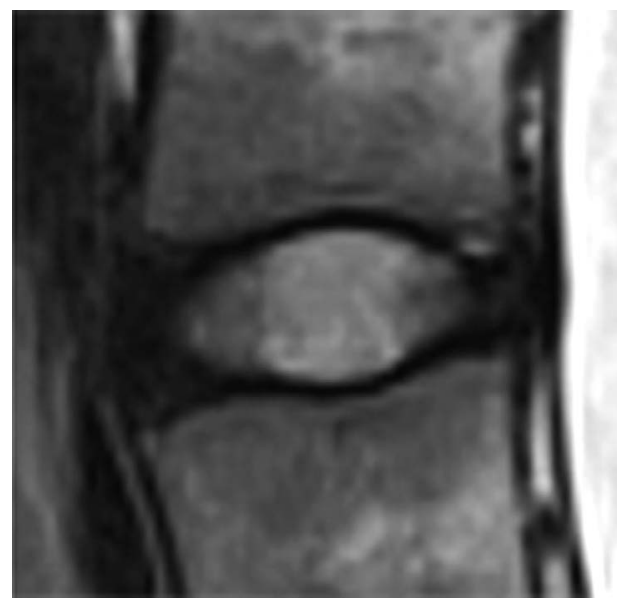

Figure 1. Pfirrmann grade I

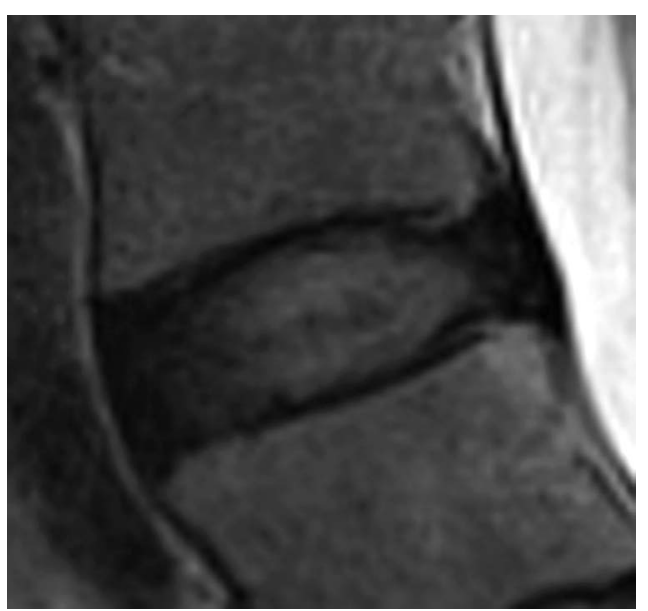

Figure 2. Pfirrmann grade II 


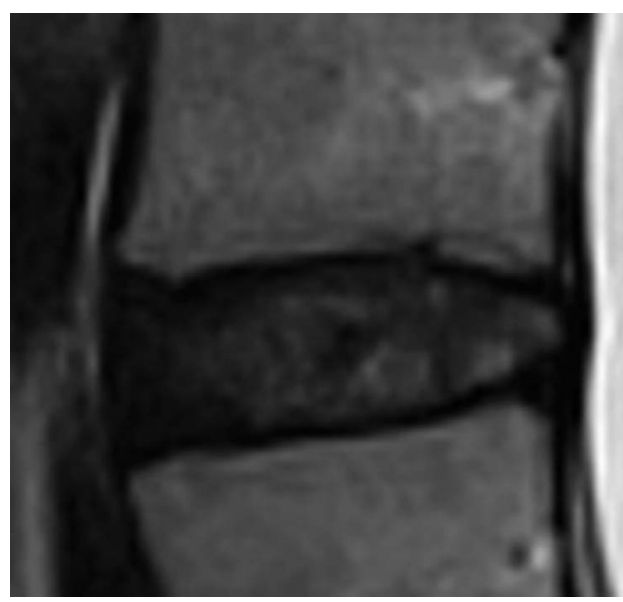

Figure 3. Pfirrmann grade III

the geometric centre as a parameter of nucleus pulposus homogeneity [16]. In their study, in $85.8 \%$ of studied intervertebral discs the weighted centre was located posterior to the geometric centre, and the distance between these centres on the longitudinal axis was significantly shorter in homogenous than in heterogenous discs.

Asymptomatic intervertebral disc degenerative changes have been widely reported before [2,17-33]. Their occurrence increases with lower assessed lumbar level and is most frequent at L5/S1 [23-25,27,30,32,34]. Older age groups are associated with a higher prevalence of these abnormalities [2,23-25,27,29-32]; however, many studies have shown that IDD occurs in all age groups, even in adolescents or young adults, despite the absence of low back pain (LBP) [19,21,28,34-36]. Correlation between the appearance of IDD in imaging studies and back pain is not explicit [26,37]. Carragee et al. performed lumbar spine MR in 200 participants with no previous history of low back pain and monitored them in a 5-year observational study. In the case of a new severe low back pain (LBP) episode, subjects were assessed for new imaging tests. Out of 51 re-evaluated subjects, 43 (84\%) had either unchanged MR or showed regression of baseline changes [38]. MR studies of symptomatic patients with IDD appearance should be evaluated considering other abnor-

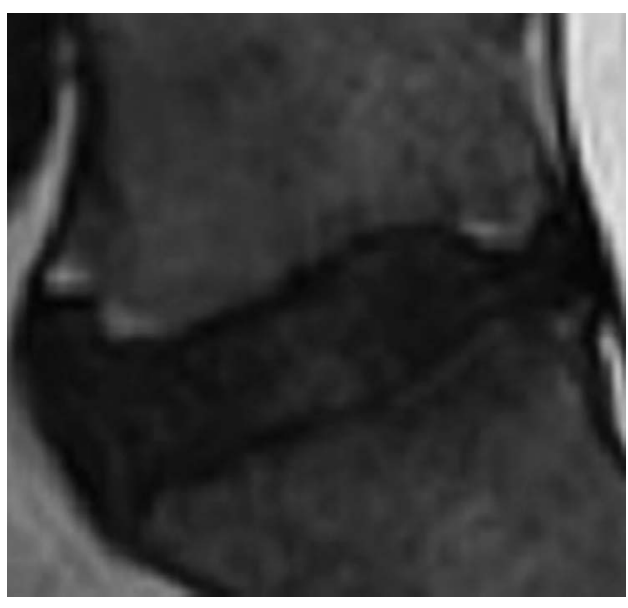

Figure 4. Pfirrmann grade IV

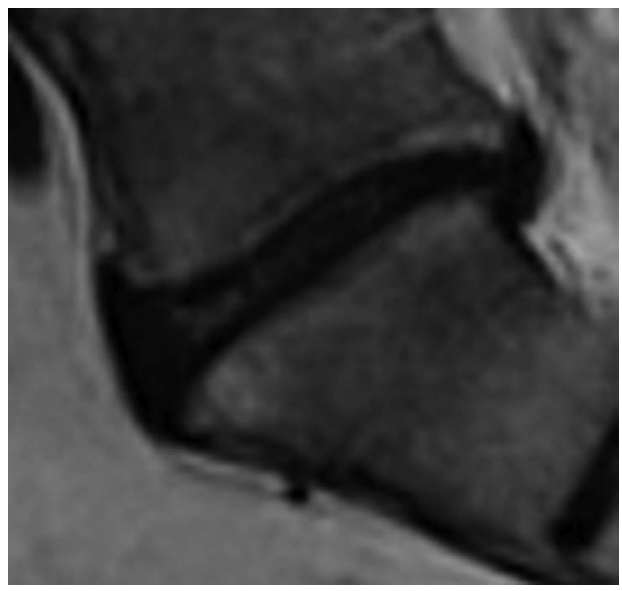

Figure 5. Pfirrmann grade V

malities that may cause pain, such as Modic changes [39], Schmorl's nodes [40], or spinal stenosis [41,42].

Brinjikji et al. reviewed 33 studies assessing age-related changes of the spine in MR among asymptomatic populations. Their results are presented in Table 2. Degenerative changes of the intervertebral discs, decrease in their height, reduction of the intensity of the $\mathrm{T} 2$ signal, bulging, and the degeneration of intervertebral joints were documented in almost $90 \%$ of asymptomatic patients over 60 years old,

Table 2. Age-specific prevalence estimates of degenerative spine imaging findings in asymptomatic patients (Brinjikji et al. paper [1])

\begin{tabular}{|l|c|c|c|c|c|c|c|}
\hline & \multicolumn{9}{|c|}{ Age groups (years) } \\
\hline Imaging features & 20 & 30 & 40 & 50 & 60 & 70 & 80 \\
\hline Disc degeneration & $37 \%$ & $52 \%$ & $68 \%$ & $80 \%$ & $88 \%$ & $93 \%$ & $96 \%$ \\
\hline Disc signal loss & $17 \%$ & $33 \%$ & $54 \%$ & $73 \%$ & $86 \%$ & $94 \%$ & $97 \%$ \\
\hline Disc height loss & $24 \%$ & $34 \%$ & $45 \%$ & $56 \%$ & $67 \%$ & $76 \%$ & $84 \%$ \\
\hline Disc bulge & $30 \%$ & $40 \%$ & $50 \%$ & $60 \%$ & $69 \%$ & $77 \%$ & $84 \%$ \\
\hline Disc protrusion & $29 \%$ & $31 \%$ & $33 \%$ & $36 \%$ & $38 \%$ & $40 \%$ & $43 \%$ \\
\hline Annular fissure & $19 \%$ & $20 \%$ & $22 \%$ & $23 \%$ & $25 \%$ & $27 \%$ & $29 \%$ \\
\hline Facet degeneration & $4 \%$ & $9 \%$ & $18 \%$ & $32 \%$ & $50 \%$ & $69 \%$ & $83 \%$ \\
\hline Spondylolisthesis & $3 \%$ & $5 \%$ & $8 \%$ & $14 \%$ & $23 \%$ & $35 \%$ & $50 \%$ \\
\hline
\end{tabular}


which suggests that such changes, especially those that were diagnosed accidentally, might be considered as a natural part of the aging process and do not require therapeutic intervention. However, protrusion of the intervertebral disc and annular fissures did not show a significant increase in the incidence with the increase of the patient's age, which may suggest that they are not part of the natural aging process [1].

The prevalence of degenerative features may also vary between different populations. Rajeswaran et al. studied lumbar spine MRI studies of 98 asymptomatic junior elite tennis players in the mean age of 18 years [43]. They found that $89.7 \%$ of them had facet joint arthropathy, $62.2 \%$ had disc degeneration, and $30.6 \%$ had disc herniation. However, in most cases, these pathological findings were mild ( $84.5 \%, 76.2 \%$, and $86.1 \%$, respectively). Ranson et al. described $61 \%$ cases of IDD among 36 asymptomatic professional fast bowlers in cricket, and one-third of them were classified as Pfirrmann IV or V. Moreover, $81 \%$ of them had stress reaction or stress fracture of pars interarticularis. However, other authors reported no significant increase in degenerative changes in middle-aged male athletes [44] or young female dancers [45]. Likewise, according to Weinreb et al., pregnancy was not associated with an increased IDD rate [46]. Savage et al. studied 149 men of 5 different occupations (including car production workers, ambulance men, and office staff) and found no correlation between lumbar spine MRI appearance and employment group or their low back pain history.

Gwak et al. studied 10 patients with asymptomatic intervertebral disc degeneration and 10 healthy asymptomatic participants, and evaluated core muscle crosssectional area (CSA) in MRI scans and their function using strength sensor, various endurance tests, and stability test. Subsequently, they compared those results between asymptomatic participants with and without intervertebral disc degeneration in magnetic resonance imaging [47]. They found no significant difference in CSA and muscle function between both groups, which might help in future differentiation between accidental findings concerning intervertebral discs from pathologies that cause patients syndromes; however, further studies should be performed.

\section{Osteophytes}

Vertebral osteophyte development is believed to be a common feature of various conditions, including aging, intervertebral disc degeneration, and obesity [48-51]. Many studies have focused on describing osteophyte formation patterns among spine regions related to various factors, including age, sex, BMI, race, and others. Several ageestimation systems evaluating vertebral osteophytes have been proposed $[48,52,53]$.

Nathan studied the prevalence of vertebral osteophytes in the spine among 400 skeletons of people who died at between 11 and 105 years of age. The osteophytes of the anterior and lateral edges of the vertebral bodies occurred with a high frequency. In cadavers over 40 years, anterior and lateral osteophytes were found in $100 \%$ of cases. Posterior osteophytes, however, occurred in the minority of cases. Thus, it may indicate that osteophytes of the anterior and lateral edges of the vertebral bodies are formed as a result of the natural aging process. In contrast, osteophytes of the posterior edges of the vertebra should not be interpreted by a radiologist as a normal finding [51].

Kacar et al. retrospectively reviewed computed tomography images of the thoracolumbar spine of 564 adult individuals ( 279 males and 285 females; between 20 and 86 years of age) to assess the effect of age and sex on the severity and localization of osteophyte formation. They reported an increase in osteophyte score between 40 and 70 years of age in both sexes, while in the lower segments of thoracic spine, males showed a significantly higher frequency of osteophytes than females.

\section{Bone marrow}

The bone marrow is a cell-rich connective tissue located inside the bone marrow cavity. It consists of 2 components - hematopoietic (red) and fatty (yellow) marrow. MRI is a very sensitive method of bone marrow imaging due to its accurate distinction between the fat content of the yellow marrow and the haematopoietic content of red marrow $[54,55]$. The distinction between bone marrow types is best seen on T1-weighted and fat-suppressed sequences [55]. The yellow marrow has a high signal intensity similar to that of subcutaneous fat, while the red marrow has an intermediate signal that is less intense than subcutaneous fat, but more intense than the intervertebral disc or muscle tissue.

At birth, nearly all bone marrow is haematopoietically active and consists exclusively of red bone marrow [55]. As the body matures, the red bone marrow gradually converts to yellow bone marrow $[55,56]$. Bone marrow conversion typically follows Neumann's law, which means that it starts from the distal phalanges and then runs towards the proximal bones and to the axial skeleton. A mature pattern of bone marrow distribution is achieved at about 25 years of age [55,56]. At this age, the haematopoietic marrow is located in the axial skeleton, sternum, ribs, and a lesser amount in proximal parts of the humerus and femur. Above this age, there is a slow, gradual further transformation of the red marrow into yellow marrow [55].

From adolescence to old age, men show a gradual, steady increase in bone marrow fat content. For women, this increase is linear up to around 55 years of age [57]. Then, bone marrow conversion accelerates in women between 55 and 65 years old $[57,58]$. There is a rapid decrease in the concentrations of oestrogens in the perimenopausal period, which results in a change in the pattern of fat distribution in the body, increasing the amount of visceral fat and fat contained in the bone marrow [57]. 


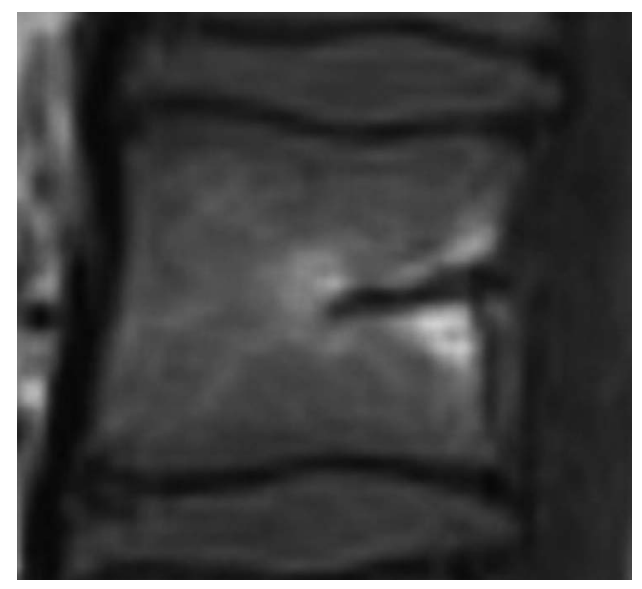

Figure 6. Pattern 1 of bone marrow distribution. T1 sagittal

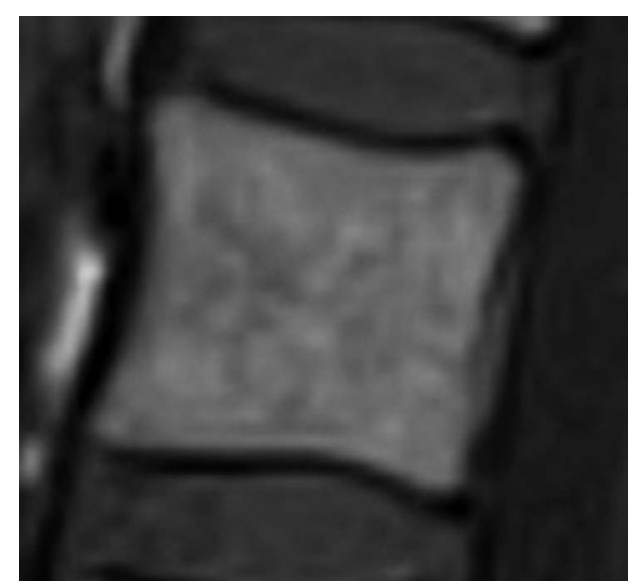

Figure 8. Pattern 3a of bone marrow distribution. T1 sagittal

The trend of the relatively high share of yellow bone marrow in men compared to women is reversed. Over the age of 60 years, the bone marrow fat content is about $10 \%$ higher in women [57].

Few studies have described common anatomic sites of red and yellow bone marrow in the spine $[54,59,60]$.

Ricci et al. studied MRI images of the axial skeleton in patients without known bone marrow abnormality, who ranged in age from 6 months to over 70 years, including 70 examinations each of the skull, cervical spine, thoracic spine, lumbar spine, pelvis, and proximal femur.

They described 4 typical patterns of bone marrow distribution in the vertebral bodies:

- Pattern 1 - high signal-intensity fatty marrow is seen confined to linear areas along the basivertebral veins (Figure 6);

- Pattern 2 - band-like and triangular areas of fatty marrow are located peripherally (Figure 7);

- Pattern 3a - multiple small areas of high intensity of fatty marrow (Figure 8);

- Pattern 3b - multiple, relatively large, well-marginated areas of fatty marrow (Figure 9).

The frequency of occurrence of bone marrow distribution patterns was different depending on the age of the

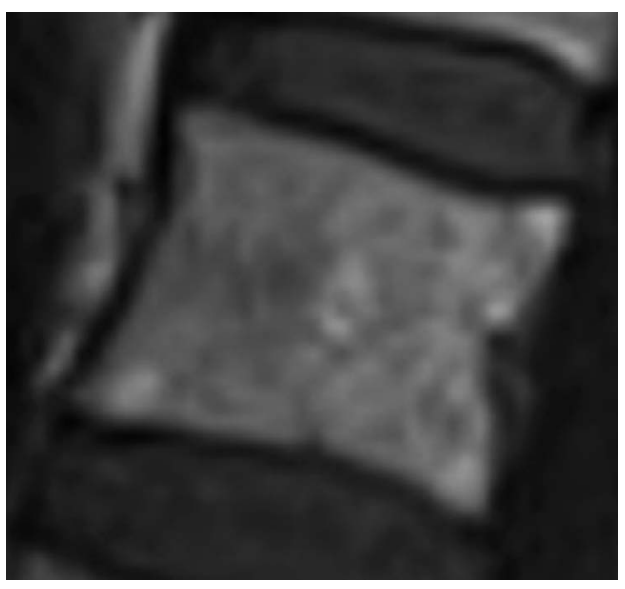

Figure 7. Pattern 2 of bone marrow distribution. T1 sagittal

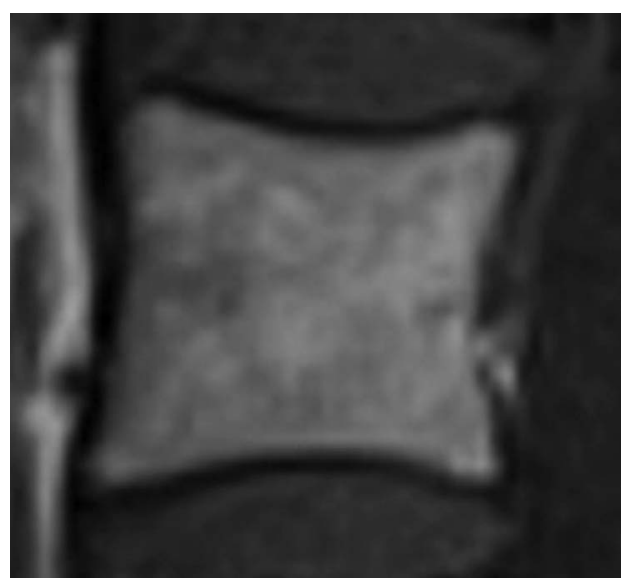

Figure 9. Pattern 3b of bone marrow distribution. T1 sagittal

patient - in people under 30 years old, the most common was pattern 1, the frequency of patterns 2 and 3 increased with age [54].

\section{Conclusions}

MRI remains a useful tool in evaluating the aging features of the spine. Many abnormalities occur widely in older asymptomatic patients. Early signs of spine aging include intervertebral disc signal changes, disc height loss, and bulging. Osteophytes of anterior and lateral edges of vertebral bodies frequently develop in people over 40 years old, whereas those of posterior edges are seen in a minority of cases, which may indicate an abnormal condition. Bone marrow fat content increases gradually with age, with acceleration in women between 55 and 65 years old. Also, yellow and red marrow distribution follows characteristic patterns depending on the patient's age. Knowledge of the prevalence of these changes is essential in the appropriate evaluation of spine imaging studies.

\section{Conflict of interest}

The authors report no conflict of interest. 


\section{References}

1. Brinjikji W, Luetmer PH, Comstock B, et al. Systematic literature review of imaging features of spinal degeneration in asymptomatic populations. AJNR Am J Neuroradiol 2015; 36: 811-816.

2. Boden SD, Davis DO, Dina TS, et al. Abnormal magnetic-resonance scans of the lumbar spine in asymptomatic subjects. A prospective investigation. J Bone Joint Surg Am 1990; 72: 403-408.

3. Nakashima H, Yukawa Y, Suda K, et al. Abnormal findings on magnetic resonance images of the cervical spines in 1211 asymptomatic subjects. Spine (Phila Pa 1976) 2015; 40: 392-398.

4. Kushchayev SV, Glushko T, Jarraya M, et al. ABCs of the degenerative spine. Insights Imaging 2018; 9: 253-274

5. Sasiadek MJ, Bladowska J. Imaging of degenerative spine disease the state of the art. Adv Clin Exp Med 2012; 21: 133-142.

6. Wáng YXJ, Wu AM, Ruiz Santiago F, et al. Informed appropriate imaging for low back pain management: a narrative review. J Orthop Translat 2018; 15: 21-34.

7. Humzah MD, Soames RW. Human intervertebral disc: structure and function. Anat Rec 1988; 220: 337-356

8. Del Grande F, Maus TP, Carrino JA. Imaging the intervertebral disk: age-related changes, herniations, and radicular pain. Radiol Clin North Am 2012; 50: 629-649.

9. Pfirrmann CW, Metzdorf A, Zanetti M, et al. Magnetic resonance classification of lumbar intervertebral disc degeneration. Spine (Phila Pa 1976) 2001; 26: 1873-1878.

10. Waldenberg C, Hebelka H, Brisby $\mathrm{H}$, et al. Differences in IVD characteristics between low back pain patients and controls associated with HIZ as revealed with quantitative MRI. PLoS One 2019; 14: e0220952.

11. Foltz MH, Kage CC, Johnson CP, et al. Noninvasive assessment of biochemical and mechanical properties of lumbar discs through quantitative magnetic resonance imaging in asymptomatic volunteers. J Biomech Eng 2017; 139: 1110021-1110027.

12. Silcox DH 3rd, Horton WC, Silverstein AM. MRI of lumbar intervertebral discs. Diurnal variations in signal intensities. Spine (Phila Pa 1976) 1995; 20: 807-811; discussion 811-812.

13. Karakida O, Ueda H, Ueda M, et al. Diurnal T2 value changes in the lumbar intervertebral discs. Clin Radiol 2003; 58: 389-392.

14. Danielson B, Willen J. Axially loaded magnetic resonance image of the lumbar spine in asymptomatic individuals. Spine (Phila Pa 1976) 2001; 26: 2601-2606.

15. Pfirrmann CW, Metzdorf A, Elfering A, et al. Effect of aging and degeneration on disc volume and shape: a quantitative study in asymptomatic volunteers. J Orthop Res 2006; 24: 1086-1094.

16. Yang SH, Espinoza Orías AA, Pan CC, et al. Spatial geometric and magnetic resonance signal intensity changes with advancing stages of nucleus pulposus degeneration. BMC Musculoskelet Disord 2017; 18: 473.

17. Boden SD, Riew KD, Yamaguchi K, et al. Orientation of the lumbar facet joints: association with degenerative disc disease. J Bone Joint Surg Am 1996; 78: 403-411.

18. Boos N, Rieder R, Schade V, et al. 1995 Volvo Award in clinical sciences. The diagnostic accuracy of magnetic resonance imaging, work perception, and psychosocial factors in identifying symptomatic disc herniations. Spine (Phila Pa 1976) 1995; 20: 2613-2625.
19. Erkintalo MO, Salminen JJ, Alanen AM, et al. Development of degenerative changes in the lumbar intervertebral disk: results of a prospective MR imaging study in adolescents with and without low-back pain. Radiology 1995; 196: 529-533.

20. Feng T, Zhao P, Liang G. Clinical significance on protruded nucleus pulposus: a comparative study of 44 patients with lumbar intervertebral disc protrusion and 73 asymptomatic control in tridimentional computed tomography. Zhongguo Zhong Xi Yi Jie He Za Zhi 2000; 20: 347-349.

21. Gibson MJ, Szypryt EP, Buckley JH, et al. Magnetic resonance imaging of adolescent disc herniation. J Bone Joint Surg Br 1987; 69: 699-703

22. Greenberg JO, Schnell RG. Magnetic resonance imaging of the lumbar spine in asymptomatic adults. Cooperative study - American Society of Neuroimaging. J Neuroimaging 1991; 1: 2-7.

23. Jarvik JJ, Hollingworth W, Heagerty P, et al. The Longitudinal Assessment of Imaging and Disability of the Back (LAIDBack) Study: baseline data. Spine (Phila Pa 1976) 2001; 26: 1158-1166.

24. Jensen MC, Brant-Zawadzki MN, Obuchowski N, et al. Magnetic resonance imaging of the lumbar spine in people without back pain. N Engl J Med 1994; 331: 69-73.

25. Kanayama M, Togawa D, Takahashi C, et al. Cross-sectional magnetic resonance imaging study of lumbar disc degeneration in 200 healthy individuals. J Neurosurg Spine 2009; 11: 501-507.

26. Kovacs FM, Arana E, Royuela A, et al. Disc degeneration and chronic low back pain: an association which becomes nonsignificant when endplate changes and disc contour are taken into account. Neuroradiology 2014; 56: 25-33.

27. Matsumoto M, Okada E, Toyama Y, et al. Tandem age-related lumbar and cervical intervertebral disc changes in asymptomatic subjects. Eur Spine J 2013; 22: 708-713.

28. Paajanen H, Erkintalo M, Kuusela T, et al. Magnetic resonance study of disc degeneration in young low-back pain patients. Spine (Phila Pa 1976) 1989; 14: 982-985.

29. Paajanen H, Erkintalo M, Parkkola R, et al. Age-dependent correlation of low-back pain and lumbar disc regeneration. Arch Orthop Trauma Surg 1997; 116: 106-107.

30. Savage RA, Whitehouse GH, Roberts N. The relationship between the magnetic resonance imaging appearance of the lumbar spine and low back pain, age and occupation in males. Eur Spine J 1997; 6: 106-114

31. Stadnik TW, Lee RR, Coen HL, et al. Annular tears and disk herniation: prevalence and contrast enhancement on MR images in the absence of low back pain or sciatica. Radiology 1998; 206: 49-55.

32. Weishaupt D, Zanetti M, Hodler J, et al. MR imaging of the lumbar spine: prevalence of intervertebral disk extrusion and sequestration, nerve root compression, end plate abnormalities, and osteoarthritis of the facet joints in asymptomatic volunteers. Radiology 1998; 209: 661-666.

33. Edmondston SJ, Song S, Bricknell RV, et al. MRI evaluation of lumbar spine flexion and extension in asymptomatic individuals. Man Ther 2000; 5: 158-164

34. Zobel BB, Vadalà G, Del Vescovo R, et al. T1rho magnetic resonance imaging quantification of early lumbar intervertebral disc degeneration in healthy young adults. Spine (Phila Pa 1976) 2012; 37: 12241230. 
35. Takatalo J, Karppinen J, Niinimäki J, et al. Association of modic changes, Schmorl's nodes, spondylolytic defects, high-intensity zone lesions, disc herniations, and radial tears with low back symptom severity among young Finnish adults. Spine (Phila Pa 1976) 2012; 37: 1231-1239.

36. Szypryt EP, Twining P, Mulholland RC, et al. The prevalence of disc degeneration associated with neural arch defects of the lumbar spine assessed by magnetic resonance imaging. Spine (Phila Pa 1976) 1989; 14: 977-981.

37. Modic MT, Ross JS. Lumbar degenerative disk disease. Radiology 2007; 245: 43-61.

38. Carragee E, Alamin T, Cheng I, et al. Are first-time episodes of serious LBP associated with new MRI findings? Spine J 2006; 6: 624-635.

39. Kjaer P, Leboeuf-Yde Ch, Korsholm L, et al. Magnetic resonance imaging and low back pain in adults: a diagnostic imaging study of 40-yearold men and women. Spine (Phila Pa 1976) 2005; 30: 1173-1180.

40. Hamanishi C, Kawabata T, Yosii T, et al. Schmorl's nodes on magnetic resonance imaging. Their incidence and clinical relevance. Spine (Phila Pa 1976) 1994; 19: 450-453.

41. Kalichman L, Kim DH, Li L, et al. Computed tomography-evaluated features of spinal degeneration: prevalence, intercorrelation, and association with self-reported low back pain. Spine J 2010; 10: 200-208.

42. Dora C, Wälchli B, Elfering A, et al. The significance of spinal canal dimensions in discriminating symptomatic from asymptomatic disc herniations. Eur Spine J 2002; 11: 575-581.

43. Rajeswaran G, Turner M, Gissane C, et al. MRI findings in the lumbar spines of asymptomatic elite junior tennis players. Skeletal Radiol 2014; 43: 925-932.

44. Healy JF, Healy BB, Wong WH, et al. Cervical and lumbar MRI in asymptomatic older male lifelong athletes: frequency of degenerative findings. J Comput Assist Tomogr 1996; 20: 107-112.

45. Capel A, Santonja Medina F, Medina D, et al. Magnetic resonance study of lumbar disks in female dancers. Am J Sports Med 2009; 37: 1208-1213.

46. Weinreb JC, Wolbarsht LB, Cohen JM, et al. Prevalence of lumbosacral intervertebral disk abnormalities on MR images in pregnant and asymptomatic nonpregnant women. Radiology 1989; 170 (1 Pt 1): 125-128.

47. Gwak GT, Hwang UJ, Jung SH, et al. Comparison of MRI crosssectional area and functions of core muscles among asymptomatic individuals with and without lumbar intervertebral disc degeneration. BMC Musculoskelet Disord 2019; 20: 576.
48. Kacar E, Unlu E, Beker-Acay M, et al. Age estimation by assessing the vertebral osteophytes with the aid of 3D CT imaging. Australian Journal of Forensic Sciences 2017; 49: 449-458.

49. Van der Merwe AE, Işcan MY, L'Abbè EN. The pattern of vertebral osteophyte development in a South African population. Int J Osteoarchaeol 2006; 16: 459-464.

50. Zukowski LA, Falsetti AB, Tillman MD. The influence of sex, age and BMI on the degeneration of the lumbar spine. J Anat 2012; 220: 57-66.

51. Nathan H. Osteophytes of the vertebral column: an anatomical study of their development according to age, race, and sex with considerations as to their etiology and significance. JBJS 1962; 44: 243-268.

52. Praneatpolgrang S, Prasitwattanaseree S, Mahakkanukrauh P. Age estimation equations using vertebral osteophyte formation in a Thai population: comparison and modified osteophyte scoring method. Anat Cell Biol 2019; 52: 149-160.

53. Watanabe S, Terazawa K. Age estimation from the degree of osteophyte formation of vertebral columns in Japanese. Leg Med (Tokyo) 2006; 8: 156-160.

54. Ricci C, Cova M, Kang YS, et al. Normal age-related patterns of cellular and fatty bone marrow distribution in the axial skeleton: MR imaging study. Radiology 1990; 177: 83-88.

55. Blebea JS, Houseni M, Torigian DA, et al. Structural and functional imaging of normal bone marrow and evaluation of its age-related changes. Semin Nucl Med 2007; 37: 185-194.

56. Laor T, Jaramillo D. MR imaging insights into skeletal maturation: what is normal? Radiology 2009; 250: 28-38.

57. Griffith JF, Yeung DKW, Ma HT, et al. Bone marrow fat content in the elderly: a reversal of sex difference seen in younger subjects. J Magn Reson Imaging 2012; 36: 225-230.

58. Baum T, Rohrmeier A, Syväri J, et al. Anatomical variation of agerelated changes in vertebral bone marrow composition using chemical shift encoding-based water-fat magnetic resonance imaging. Front Endocrinol (Lausanne) 2018; 9: 141.

59. Moulopoulos LA, Koutoulidis V. MRI of the normal bone marrow: anatomic sites. In: Bone Marrow MRI: A Pattern-Based Approach. Moulopoulos LA, Koutoulidis V (eds.). Springer Milan, Milano 2015. p. 25-34.

60. Shah LM, Hanrahan CJ. MRI of spinal bone marrow: part I, techniques and normal age-related appearances. AJR Am J Roentgenol 2011; 197: 1298-1308. 